\title{
Práticas e Estágios de Odontologia Como Estratégias de Mudanças Para Formação no SUS
}

\author{
Cenise Cristina Zago Cassiano ${ }^{1}$, Bibiana Arantes Moraes ${ }^{2}$, Nilce Maria da Silva Campos Costa ${ }^{3}$
}

\begin{abstract}
RESUMO
Este estudo buscou analisar as atividades desenvolvidas nos estágios e práticas do curso de Graduação em Odontologia de uma instituição pública federal de Ensino Superior, inserido no Programa Nacional da Formação em Saúde (Pró-Saúde) e Programa de Educação pelo Trabalho para a Saúde (PET-Saúde). Foram analisados o Estágio de Odontologia Coletiva II e o Estágio não curricular do PET-Saúde/Rede de Atenção à Saúde, por meio da descrição das atividades de formação profissional vivenciadas no Sistema Único de Saúde (SUS) sob a perspectiva do preceptor. Realizou-se um estudo de abordagem qualitativa e triangulação de dados por intermédio da análise documental do projeto político pedagógico do curso e do guia do estágio, a observação participante no campo de estágio e a análise de conteúdo das entrevistas semiestruturadas com preceptores dos estágios. Os resultados demonstraram o predomínio da formação orientada pelas Diretrizes Curriculares Nacionais (DCNs) e a contribuição dos programas citados na integração ensino-serviço-comunidade, favorecendo a execução das DCNs nos cenários de prática. A interprofissionalidade, entretanto, encontra-se incipiente, sendo observada a falta de clareza e de disposição dos atores envolvidos para desenvolvê-la. A pesquisa indicou que a realização dos estágios trouxe aos estudantes oportunidades de aprendizagem, reflexão e compreensão do SUS.
\end{abstract}

Palavras-chave: Formação profissional. Odontologia. Sistema Único de Saúde.

\section{ANALYSIS OF TRAINING AND INTERNSHIPS IN ODONTOLOGY AND OPPORTUNITIES FOR CHANGE IN BRAZILIAN PUBLIC HEALTH TRAINING}

\begin{abstract}
The goal of this study was to analyze internships and practical training activities in the undergraduate course in odontology at a federal public institution of higher education, provided by Pró-Saúde (National Program of Training in Health) and PET-Saúde (Program of On-the-job Training in Health). The study analyzed Group Training in Odontology Stage II and the non-curricular module of PET-Saúde/Health Care Network training, through documentation of professional training activities in the Brazilian public health system (SUS), from the perspective of the trainer. A qualitative study with data triangulation was carried out through documentary analysis of the pedagogical documentation of the course as well as the course guide itself, participant observation in the field of the internship or training, and content analysis of semi-structured interviews with trainers of the modules. The results showed the predominance of the training was guided by the National Curricular Guidelines $(D C N)$ with the contribution of programs cited in teaching-service-community integration, favoring the implementation of the $D C N$ in practical situations. The interprofessionality, however, is incipient, reflecting a lack of clarity and willingness of the professionals involved to develop it. This research endorses the continued participation of students in internships and other opportunities for learning, reflection and understanding of SUS.
\end{abstract}

Keywords: Professional formation. Odontology. Sistema Único de Saúde.

\footnotetext{
Nutricionista. Mestre em Ensino na Saúde - UFG. Docente - PUC/GO. http://lattes.cnpq.br/3206499974533622. https://orcid.org/0000-0003-4998-3565. cenisezago@hotmail.com

${ }^{2}$ Nutricionista. Doutoranda em Ciências em Saúde - UFG. http://lattes.cnpq.br/4400053710065368. https://orcid.org/0000-0001-9312-4595. bibiananutri20@gmail.com

${ }^{3}$ Nutricionista. Doutora em Educação - PUC. Docente - UFG. http://lattes.cnpq.br/6977373149115047. https://orcid.org/0000-0003-2531-1430. nilcecosta58@gmail.com
} 


\section{INTRODUÇÃO}

A formação de recursos humanos em saúde necessita de investimentos de forma eficaz. Para tanto, associar a educação à saúde é fundamental para a promoção da vida e para suprir as deficiências de profissionais na atenção básica de saúde no Sistema Único de Saúde (ALMEIDA; VON; FERRAZ, 2008). Desde 2001, os Ministérios da Saúde e da Educação homologaram as Diretrizes Curriculares Nacionais (DCNs) como norteadoras da formação em saúde no Brasil, respeitando os princípios do SUS e atendendo às especificidades dos serviços de saúde e da população (BRASIL, 2001).

Além delas, outros estímulos a mudanças na formação foram disponibilizados às instituições de Ensino Superior por iniciativa governamental, como o Programa Nacional de Reorientação da Formação Profissional em Saúde (Pró-Saúde) e o Programa de Educação pelo Trabalho para a Saúde (PET-Saúde) que, atendendo às DCNs, buscaram a integralidade do cuidado em um olhar generalista, crítico, reflexivo e ético (BRASIL, 2005; BRASIL, 2008; BRASIL, 2001).

As políticas públicas de saúde enfatizam a necessidade de produção de práticas de saúde resolutivas para a formação de profissionais com ênfase na atenção básica. Neste sentido, a integralidade deve constituir-se em eixo principal de orientação dos atendimentos de saúde prestados à comunidade, demonstrando a importância dos movimentos de reorientação da formação em saúde, associados às DCNs, para um ensino que compreenda a realidade vivenciada nos serviços de saúde (FERREIRA; COTTA; OLIVEIRA, 2009).

Apesar dos avanços conquistados, a formação profissional na área da saúde ainda está ancorada em modelos fragmentados, em ciclos básicos e profissionais, fora do contexto dos serviços públicos de saúde, com enfoque pedagógico tradicional. Com essa formação, os profissionais raramente reproduzem no serviço a abordagem interdisciplinar, o que resulta na sobreposição das ações de cuidado (MORAES; COSTA, 2016).

Diante da necessidade de nova formação em saúde, esta pesquisa objetivou analisar as atividades realizadas por estudantes de odontologia de uma Instituição Pública Federal de Ensino Superior, em um estágio curricular em Odontologia Coletiva e em um estágio não curricular, o do Pet-Saúde/RAS (Rede de Atenção em Saúde) nos cenários de prática da atenção básica em saúde.

\section{METODOLOGIA}

Foi realizado um estudo descritivo e exploratório com abordagem qualitativa. A coleta de dados foi desenvolvida em três etapas: 1) observação participante dos estágios em Odontologia Coletiva II (EOC II) e no Programa de Educação pelo Trabalho (PET Saúde/RAS); 2) entrevistas semiestruturadas; e 3) análise dos seguintes documentos: a) Diretrizes Curriculares Nacionais para os Cursos de Odontologia; b) Projeto Pedagógico do curso de Odontologia estudado; e c) Guia e Plano de Ensino do Estágio de Odontologia Coletiva Il e Edital do PET Saúde/RAS.

Na primeira etapa - observação participante os campos de investigação foram: 1) uma Unidade Básica de Saúde (UBS) da Secretaria Municipal de Saúde (SMS) de Goiânia; 2) uma escola municipal; e 3) residências da área de abrangência da UBS na região leste de Goiânia. O critério para a escolha da UBS foi a presença de estudantes cursando estágios curriculares e bolsistas PET-Saúde/RAS do curso de odontologia da Instituição de Ensino Superior (IES) estudada. O acesso aos campos de investigação e início da coleta de dados deu-se pela anuência da SMS.

A população observada foi constituída por 2 cirurgiões-dentistas, que atuavam como preceptores de estágio do curso de odontologia, e 1 cirurgião-dentista, preceptor do estágio não curricular PET-Saúde/ RAS, além de 13 estagiários que cursavam o oitavo período do curso.

O registro da observação das atividades foi realizado na forma de diário de campo. A observação constitui-se em um instrumento imprescindível na captação da realidade dos participantes e na corroboração dos dados obtidos nas demais etapas da investigação (MINAYO, 2014).

$\mathrm{Na}$ segunda etapa do estudo foram realizadas entrevistas semiestruturadas com os preceptores dos estágios EOC e Pet-Saúde/RAS. As entrevistas foram gravadas e transcritas para posterior análise na modalidade Análise de Conteúdo Temática (BARDIN, 2011; MINAYO, 2014). Buscou-se a compreensão das informações apreendidas nas falas dos sujeitos por meio das questões norteadoras presentes no roteiro das entrevistas, aliadas aos dados obtidos na observação do campo (MINAYO, 2014).

Para a análise e interpretação dos dados foi estabelecida a triangulação entre as falas obtidas com as entrevistas, a descrição do diário de campo e os documentos norteadores do curso de odontologia (MINAYO, 2014). 
Esta pesquisa obedeceu os princípios e postulados éticos de acordo com a Resolução do ConseIho Nacional de Saúde (CNS) no 466/2012 (BRASIL, 2014). O projeto de pesquisa foi aprovado pelo Comitê de Ética em Pesquisada UFG, sob o protocolo no $571.173 / 2014$, e todos os participantes assinaram o Termo de Consentimento Livre e Esclarecido (TCLE).

\section{RESULTADOS E DISCUSSÃO}

Os resultados serão apresentados em quadros com resumos das atividades desenvolvidas pelos estudantes nos locais de estágios sob supervisão de pre- ceptores, posto que algumas foram acompanhadas também por docentes. Foram tomados como referenciais teóricos para a análise das categorias as DCNs para o curso, o guia do EOC e o edital do PET-Saúde/ RAS.

Observa-se que todas as atividades realizadas pelos estudantes estão previstas nos documentos norteadores do estágio, Plano de Ensino, Edital do PET/ RAS e DCNs.

Quadro 1 - Observação de atividades do estágio no Centro de Saúde Escola e comparação com os documentos norteadores, Goiânia, 2015

\begin{tabular}{|c|c|c|c|c|}
\hline Local: UBS & Supervisão & $\begin{array}{l}\text { Atividade dos } \\
\text { estagiários }\end{array}$ & $\begin{array}{c}\text { Plano de Ensino do OEC I/Edital } \\
\text { do PET-Saúde/RAS }\end{array}$ & Relação da atividade com as DCNs \\
\hline EOC II & $\begin{array}{l}\text { Preceptor } 1 \\
\text { Professor }\end{array}$ & $\begin{array}{l}\text { Apresentação } \\
\text { das atividades } \\
\text { desenvolvidas durante } \\
\text { o semestre. }\end{array}$ & $\begin{array}{l}\text { - Participar em trabalhos com } \\
\text { equipes multiprofissionais no } \\
\text { serviço público de saúde no SUS. } \\
\text { - Desenvolver reflexão crítica } \\
\text { e criativa sobre a realidade } \\
\text { mediante a diversificação dos } \\
\text { cenários de práticas. } \\
\text { - Despertar para a necessidade } \\
\text { da humanização dos serviços } \\
\text { e desenvolver o trabalho em } \\
\text { equipe mediante interação com } \\
\text { outros profissionais. }\end{array}$ & $\begin{array}{l}\text { - Presença e acompanhamento } \\
\text { do professor. } \\
\text { - Parceria ensino-serviço com } \\
\text { processo avaliativo conjunto } \\
\text { docente/preceptor. } \\
\text { - Aproximação do aluno a } \\
\text { realidade do SUS. } \\
\text { - Avaliação e reflexão do projeto } \\
\text { de estágio. } \\
\text { - Atuação em equipe } \\
\text { multiprofissional da Estratégia } \\
\text { Saúde da Família. } \\
\text { - Profissional do serviço } \\
\text { facilitador do aprendizado. }\end{array}$ \\
\hline $\begin{array}{l}\text { PET-Saúde } \\
\text { /RAS }\end{array}$ & Preceptor 2 & $\begin{array}{l}\text { Promoção de saúde } \\
\text { sobre câncer de boca } \\
\text { com abordagem em } \\
\text { grupo e entrega de } \\
\text { fôlder sobre autoexame } \\
\text { e prevenção deste } \\
\text { câncer na recepção aos } \\
\text { usuários. } \\
\\
\text { Promoção de saúde } \\
\text { sobre câncer de boca } \\
\text { em visitas domiciliares } \\
\text { com realização do } \\
\text { exame bucal pelo } \\
\text { preceptor e estagiário } \\
\text { e entrega de fôlder } \\
\text { educativo. }\end{array}$ & $\begin{array}{l}\text { - Contribuir para a formação de } \\
\text { profissionais de saúde com perfil } \\
\text { adequado às necessidades da } \\
\text { população e às políticas de saúde } \\
\text { do País; } \\
\text { - Sensibilizar e preparar } \\
\text { profissionais de saúde para o } \\
\text { enfrentamento das diferentes } \\
\text { realidades de vida e de saúde da } \\
\text { população brasileira; } \\
\text { - Aproximar o aluno da realidade } \\
\text { do SUS. }\end{array}$ & $\begin{array}{l}\text { - Diversificação dos cenários de } \\
\text { prática. } \\
\text { - Ação de promoção e prevenção } \\
\text { da saúde. } \\
\text { - Parceria ensino-serviço com } \\
\text { utilização de fôlder da FO/UFG. } \\
\text { - Profissional do serviço } \\
\text { facilitador do aprendizado. }\end{array}$ \\
\hline
\end{tabular}




\begin{tabular}{|c|l|l|l|l|}
\hline EOCII & Preceptor 1 & $\begin{array}{l}\text { Aplicação de } \\
\text { formulário avaliativo } \\
\text { sobre as atividades } \\
\text { desenvolvidas no } \\
\text { semestre para } \\
\text { estudantes e ao } \\
\text { preceptor 1, equipe e } \\
\text { demais funcionários } \\
\text { da unidade, sob } \\
\text { supervisão docente. }\end{array}$ & $\begin{array}{l}\text { - Planejar, acompanhar e } \\
\text { avaliar as atividades de estágio } \\
\text { juntamente com o estagiário } \\
\text { e a equipe colaboradora, } \\
\text { especialmente os preceptores. }\end{array}$ & $\begin{array}{l}\text { - Acompanhamento do professor. } \\
\text { - Parceria ensino-serviço/ } \\
\text { avaliação e reflexão conjunta } \\
\text { sobre o estágio. } \\
\text { - Aproximação do aluno à } \\
\text { realidade do SUS. } \\
\text { - Profissional do serviço } \\
\text { facilitador do aprendizado. }\end{array}$ \\
\hline EOCII & Preceptor 2 & $\begin{array}{l}\text { Apresentação } \\
\text { das atividades } \\
\text { desenvolvidas durante } \\
\text { o semestre, sob } \\
\text { supervisão do docente } \\
\text { e preceptor. }\end{array}$ & $\begin{array}{l}\text { - Executar atividades em equipes } \\
\text { multiprofissionais no Sús. } \\
\text { - Desenvolver reflexão crítica e } \\
\text { criativa sobre a realidade com } \\
\text { diversificação dos cenários de } \\
\text { práticas. } \\
\text { - Despertar para a necessidade } \\
\text { da humanização dos serviços e } \\
\text { desenvolvimento do trabalho em } \\
\text { equipe mediante interação com } \\
\text { outros profissionais. }\end{array}$ & $\begin{array}{l}\text { - Ação de promoção e prevenção } \\
\text { prática. } \\
\text { da saúde. } \\
\text { - Presença e acompanhamento } \\
\text { do professor. } \\
\text { - Profissional do serviço } \\
\text { facilitador do aprendizado. }\end{array}$ \\
\hline
\end{tabular}

Fonte: Dados da pesquisa/elaborado pelos pesquisadores.

Quadro 2 - Observação de atividades do estágio na Escola Municipal e comparação com os documentos norteadores, Goiânia, 2015

\begin{tabular}{|c|c|c|c|c|}
\hline $\begin{array}{l}\text { Local: Escola } \\
\text { Municipal }\end{array}$ & Supervisão & Atividade dos estudantes & $\begin{array}{c}\text { Plano de Ensino do OEC I/Edital do PET- } \\
\text { Saúde/RAS }\end{array}$ & $\begin{array}{l}\text { Relação da atividade } \\
\text { com as DCNs }\end{array}$ \\
\hline EOCII & $\begin{array}{c}\text { Preceptor } 2 \\
\text { Docente }\end{array}$ & $\begin{array}{l}\text { Promoção da saúde } \\
\text { sobre o tema bullying } \\
\text { com os alunos da escola } \\
\text { (solicitação da escola) } \\
\text { Técnica: roda de conversa } \\
\begin{array}{l}\text { Supervisão: docente e } \\
\text { preceptor }\end{array}\end{array}$ & $\begin{array}{l}\text { - Identificar os determinantes sociais do } \\
\text { processo saúde-doença na realidade do } \\
\text { SUS. } \\
\text { - Desenvolver reflexão crítica e } \\
\text { criativa sobre a realidade, mediante a } \\
\text { diversificação dos cenários de práticas. } \\
\text { - Produzir e divulgar conhecimentos da } \\
\text { área considerando as necessidades do } \\
\text { SUS. } \\
\text { - Reconhecer a importância da } \\
\text { aproximação com realidade do SUS para } \\
\text { a formação profissional e cidadã. }\end{array}$ & $\begin{array}{l}\text { - Diversificação dos } \\
\text { cenários de prática. } \\
\text { - Ação de promoção } \\
\text { e prevenção da } \\
\text { saúde. } \\
\text { - Presença e } \\
\text { acompanhamento do } \\
\text { professor. } \\
\text { - Profissional do } \\
\text { serviço facilitador do } \\
\text { aprendizado. }\end{array}$ \\
\hline
\end{tabular}

Fonte: Dados da pesquisa/elaborado pelos pesquisadores.

Ao realizar a análise do conteúdo da observação de campo e das entrevistas, emergiram duas categorias principais: 1) contribuição dos cenários reais de prática na formação para o SUS; e 2) influência da parceria ensino-serviço sobre o processo de trabalho nos estágios e na atualização profissional.

A seguir são apresentados os resultados segundo as categorias analíticas.

\section{Contribuição dos cenários reais de prática na formação profissional para o SUS}

As observações de campo foram realizadas com a inserção dos alunos nos cenários de prática. Foi constatada a valorização dos estágios por parte dos acadêmicos e docentes que reconheceram a sua importância na formação profissional. Houve também o incentivo e a cooperação dos preceptores no aprendizado da concepção ampliada de saúde pelos estudantes.

O Quadro 3 apresenta o cotejamento dos resultados advindos da observação de campo com as entrevistas realizadas com os preceptores dos locais de estágio. Essa correlação permitiu a confirmação de dados fornecidos pelas entrevistas e pela observação de campo. 
Quadro 3 - Correlação dos eixos temáticos obtidos nas entrevistas com as observações de campo

\begin{tabular}{|c|c|}
\hline ENTREVISTA & OBSERVAÇÃO DE CAMPO \\
\hline $\begin{array}{l}\text { Contato do estagiário com cenários de prática } \\
\text { e sua contribuição na percepção do SUS }\end{array}$ & $\begin{array}{l}\text { Os estágios contemplaram vivências de situações reais do serviço na } \\
\text { atenção básica e no Programa Saúde na Escola (PSE). }\end{array}$ \\
\hline $\begin{array}{l}\text { Estagiários estimulam a atualização } \\
\text { profissional dos preceptores }\end{array}$ & $\begin{array}{l}\text { O estagiário contribuiu com a atualização dos preceptores, fato } \\
\text { observado nas atividades desenvolvidas na escola. }\end{array}$ \\
\hline $\begin{array}{l}\text { Influência da preceptoria no processo de } \\
\text { trabalho desenvolvido }\end{array}$ & $\begin{array}{l}\text { As atividades dos estagiários contemplam as demandas da equipe/ } \\
\text { unidade, contribuindo para o desenvolvimento do processo de trabalho. } \\
\text { Por exemplo, há colaboração dos acadêmicos nas ações do PSE, } \\
\text { alcançando todos os alunos da escola. }\end{array}$ \\
\hline $\begin{array}{l}\text { Contribuição para parceria ensino-serviço no } \\
\text { EOC II e PET-Saúde/RAS }\end{array}$ & $\begin{array}{l}\text { A avaliação do estágio mostrou o compromisso da academia com a prática } \\
\text { compartilhada. A programação das atividades do semestre foi realizada } \\
\text { em conjunto, e os preceptores foram convidados para o encerramento } \\
\text { do estágio. Como exemplo, as ações do PSE foram propostas pelo } \\
\text { preceptor, realizadas pelos acadêmicos e supervisionadas pelo docente. }\end{array}$ \\
\hline & $\begin{array}{l}\text { A IES oferece material educativo (fôlder) para as ações de promoção de } \\
\text { saúde bucal. }\end{array}$ \\
\hline $\begin{array}{l}\text { Presença do docente no campo de estágio de } \\
\text { EOCII }\end{array}$ & $\begin{array}{l}\text { A presença do professor responsável foi constante em todas as atividades } \\
\text { dos estagiários. }\end{array}$ \\
\hline $\begin{array}{l}\text { Diferenças entre o Estágio curricular EOC II e } \\
\text { não curricular PET-Saúde/RAS }\end{array}$ & $\begin{array}{l}\text { Foram reconhecidas diferenças nas atividades dos dois estágios sob } \\
\text { observação. OEOC II contempla o SUS de maneira ampliada, e acontece } \\
\text { em período de duração pré-determinado. No PET-Saúde/RAS, os } \\
\text { objetivos não são estabelecidos pela matriz curricular e as atividades } \\
\text { baseiam-se na promoção da saúde, mas sem o diagnóstico prévio da } \\
\text { área de abrangência e sem a presença do docente. }\end{array}$ \\
\hline $\begin{array}{l}\text { Assiduidade, compromisso e vínculo dos } \\
\text { estagiários de EOC II e dos bolsistas PET- } \\
\text { Saúde/RAS }\end{array}$ & $\begin{array}{l}\text { Todos os estagiários mostraram alto grau de compromisso e de } \\
\text { pontualidade em relação às atividades desenvolvidas. }\end{array}$ \\
\hline $\begin{array}{l}\text { Contribuição financeira da bolsa PET-Saúde } \\
\text { para preceptores responsáveis }\end{array}$ & $\begin{array}{l}\text { A bolsa foi considerada estímulo dado ao profissional, embora não } \\
\text { houvesse diferenciação na supervisão realizada pelos preceptores de } \\
\text { ambos estágios. }\end{array}$ \\
\hline
\end{tabular}

Fonte: Dados da pesquisa/elaborado pelos pesquisadores.

Durante as entrevistas com os preceptores, pôde-se identificar a influência positiva dos estágios em relação ao futuro do profissional:

Há anos atrás a gente tinha só aquela ideia fixa de sair da faculdade e ir para o consultório particular. Eles não, eles já têm esse outro lado. [...] Quando eles começam a vivenciar, a ver o que éo SUS [...] começam a abrir mais a cabeça. Você vê que depois que sai da faculdade, às vezes eles entram em contato com você para poder ter material para estudo, para prestar um concurso; já não saem com aquele foco, assim bem direcionado, só do particular. Eu acho que ajuda muito (P1).

Os resultados obtidos vão ao encontro dos achados de outras investigações. Estudo sobre o mercado de trabalho em odontologia expõe o crescimento da atuação do cirurgião-dentista no SUS e considera que a diversificação dos cenários de prática contribui para formar profissionais com uma visão ampliada da realidade para, assim, ajudar a melhorar quadros epidemiológicos do país. Outras pesquisas demonstraram que os estudantes apresentam maior sensibilidade aos problemas sociais quando vivenciam a realidade dos serviços de saúde com a diversificação dos cenários de prática. Além disso, a diversificação de cenários mostra-se como fator coadjuvante no processo de reforma curricular na universidade (FERREIRA et al., 2015; TOASSI; DAVOGLIO; LEMOS, 2012).

Esta visão foi manifestada por um dos preceptores entrevistados:

Acho que só vem acrescentar à formação profissional dele. Não dá nem para comparar; você estudar o SUS somente lá no livro e no computador, $e$ vir aqui vivenciar a realidade você vê como a 
coisa acontece, como que é a estrutura das unidades de saúde por exemplo, como é lidar com os pacientes, com a comunidade [...]. Tem a possibilidade de ver o que realmente acontece, além da teoria (P2).

O estágio de Odontologia Coletiva (EOCII) propõe a inserção de práticas com níveis de complexidades crescentes ao longo do processo de formação. Propõe também que se considere o levantamento epidemiológico e social da população atendida para, assim, realizar o planejamento conjunto das ações com as equipes multiprofissionais no SUS (UFG, 2015).

Segundo os preceptores, os estágios atendem ao Guia EOC e estão em consonância com o Projeto Pedagógico do Curso (PPC). No primeiro semestre identifica-se a realidade da população e dos serviços de saúde, e, em seguida, são desenvolvidas estratégias de ações conjuntas, ou seja, planejamento envolvendo docentes, estagiários e os profissionais do serviço.

Silva et al. (2012), ao avaliarem relatórios elaborados por 18 cursos de odontologia que participaram do Pró-Saúde, concluíram que as IES estão sensíveis à formação realizada nos espaços do SUS. Apesar disso, têm convivido com o despreparo de profissionais atuantes na atenção primária de saúde. A interdisciplinaridade foi citada como avanço nas relações multiprofissionais, mas a indisponibilidade entre os horários de trabalho dos profissionais tem sido uma dificuldade para a realização de atividades compartiIhadas.

No EOC II o planejamento e encerramento das atividades foi realizado de forma conjunta, e a avaliação ocorreu com a presença de preceptores e docentes. Segundo a literatura, "o planejamento e avaliação em conjunto refletem concretamente para a qualidade da assistência e para o desenvolvimento das habilidades profissionais" (BREHMER; RAMOS, 2016).

A inserção dos estudantes nas unidades de saúde e as mudanças produzidas por meio das práticas desenvolvidas pelo Pró-Saúde, têm sido consideradas um avanço na articulação ensino-serviço, ampliando os estágios e contribuindo com a aprendizagem e trabalho (VASCONCELOS; STEDEFELDT; FRUTUOSO, 2016). Os resultados aqui obtidos corroboram esta percepção, pois o Pró-Saúde fortalece as ações do cuidado com intervenções na formação do cirurgião-dentista de tecnicista/hospitalocêntrico para um modelo capaz de enfrentar a complexidade presente no território na atenção básica. O diálogo e a aproximação entre as partes transformam a visão docente e do profissional do serviço de saúde (ANDRADE; BOESHS; BOESHS, 2015; VASCONCELOS; STEDEFELDT; FRUTUOSO, 2016).

Dentre as diferenças entre os dois estágios observados nesta pesquisa, constatou-se que o EOC II possui maior abrangência de conteúdos e experiências na prática em relação ao PET-Saúde/RAS. Um aspecto a ser considerado é o período de duração do estágio na mesma unidade de saúde: o estágio em Odontologia Coletiva ocorre durante todo o ano, enquanto o do PET-Saúde/RAS acontece em um período três meses. Deve-se levar em conta que o EOC é curricular, o mesmo não acontecendo com o segundo. $O$ EOC, portanto, oferece maior contato e familiaridade com as estratégias do SUS, conforme a visão de um preceptor:

O estágio da odontologia coletiva [...] tem um objetivo, eu diria assim, maior. Além do estudante vir e conhecer a realidade do SUS, ele tem que aprender a identificar problemas, a fazer um diagnóstico, a elaborar um projeto, a planejar. Então ele têm objetivos mais amplos (P2).

Apesar das diferenças, ficou claro que ambos são ferramentas de aprendizagem que inserem os estudantes nas equipes de atenção básica de saúde, executam ações de educação em saúde e agregam novos saberes aos profissionais da equipe.

\section{Influência da parceria ensino-serviço sobre o processo de trabalho nos estágios e na atualização profissional dos preceptores}

Os preceptores assinalaram sua satisfação por exercer esta função, pela aproximação serviço-academia e pelo interesse em contribuir com a formação de cirurgiões-dentistas. Constatou-se nas observações de campo e entrevistas que as ações desenvolvidas proporcionaram benefícios à comunidade, como ações de promoção e prevenção da saúde bucal, e, inclusive, aos próprios preceptores:

Eu sou muito favorável à existência dos estágios;
eu acho que isso é muito bom para a comuni-
dade, para formação do profissional [...]. Todas
as vezes que a gente recebeu estagiários aqui,
sempre foi com essa ótica de trazer um beneficio
também para o usuário [...]. Eu tenho beneficio
para mim, pessoalmente como profissional, e
tem um benefício do trabalho (P2).

Ao estudar a percepção de alunos de odontologia sobre o estágio curricular na atenção básica, Toassi, Davaglio e Lemos (2012) também observaram 
a contribuição não somente para a formação de profissionais, mas também para a aproximação da academia com os serviços de saúde. Essa parceria é mencionada como necessária nas DCNs do PPC elaborado no curso de odontologia (BRASIL, 2001). Estudo sobre a preceptoria no Pró-Pet-Saúde mostra que a parceria ensino-serviço é uma maneira de alcançar o perfil de formação profissional previsto nas DCNs, sobretudo quando se trata de preceptores comprometidos com a comunidade. O Pró-Pet-Saúde transformou as práticas de ensino e aprendizagem na área da saúde, destacando-se a atividade investigativa voltada à demanda do serviço (LIMA; ROZENDO, 2015).

No Guia do EOC/15 constava como atribuição do professor orientar e supervisionar as atividades executadas pelos acadêmicos, fato observado in loco nos estágios e confirmado na narrativa do preceptor:

Na área da odontologia a gente tem todo um apoio das professoras. A gente não recebe nenhum aluno aqui sem o apoio delas. Não vem sozinho, não vem perdido, não vem solto. Então, a gente só têm ganhos aqui (P1).

A inserção dos estagiários nas equipes da Estratégia de Saúde da Família com foco no trabalho multiprofissional, estabelece o cumprimento das DCNs, como observado em todas as atividades nos estágios.

A presença dos estagiários apresentou-se como fator motivacional para as equipes de saúde, com troca de informações entre estagiários, preceptores e docentes. Foi considerada influência positiva na atualização profissional dos preceptores, possibilitando reflexões sobre a prática e oportunidade de instrumentalizar os conhecimentos em ambientes acadêmicos. Nas narrativas foram identificadas intenções de construção e busca de novos conhecimentos:

Essa para mim é uma boa forma de atualização, de estar mais atento, de me cobrar mais, de me forçar a estudar mais. Então essa situação é muito útil para mim como profissional, ao mesmo tempo em que você está ensinando, você está aprendendo também [...]. Eu acho que a gente está sempre aprendendo, e os professores também (P2).

Eu acho que é uma troca de experiência. A gente não fica só fechadinho aqui, a gente tem o contato com a universidade que te abre os horizontes e o contato com pessoas novas que trazem também conhecimentos da faculdade para cá. Eu acho assim, para mim foi um ganho, eu adorei participar. [...]. Então eu acho que às vezes nem sempre você ter uma remuneração que vai te dar mais lucro do que esse conhecimento que eu estou tendo (P1).

Assim como observado nesta investigação, estudo com enfermeiros e docentes sobre a percepção ensino-serviço verificou que os profissionais do serviço acreditam que o contato com os estudantes "fez com que eles, como profissionais, tivessem de enfrentar desafios novos e se manterem atualizados, o que contribui para a educação permanente" (ANDRADE; BOESHS; BOESHS, 2015).

Os docentes participantes deste estudo declararam que atingiram seus objetivos no ensino, e os profissionais do serviço reconheceram a parceria como satisfatória.

Em relação ao PET-Saúde/RAS, o preceptor encontra dificuldades em desenvolver ações que envolvam os profissionais não bolsistas da unidade:

Às vezes as pessoas questionavam que ela não iria participar da atividade porque ela não recebia bolsa. Apesar que a atividade era em beneficio da comunidade, mas mesmo assim algumas pessoas ficavam questionando (P2).

Lima e Rozendo (2015) também constataram essa narrativa após análise dos desafios e possibilidades de 30 preceptores do Pró-Pet/Saúde, considerando que alguns profissionais se negaram a participar de ações do Pet-Saúde por não serem contemplados com a bolsa. Sugere-se que esta foi uma falha do programa, por não conseguir beneficiar a todos preceptores, e a solução poderia um ter sido de rodízio da bolsa entre os preceptores para não haver essa negativa por parte dos trabalhadores de saúde.

Na sistematização do processo de trabalho e articulação da preceptoria com o serviço, foi unânime a expressão afirmativa dos profissionais em relação ao ganho e perspectiva de construção da promoção da saúde, com novas experiências e conhecimentos aos preceptores e demais profissionais:

Eu acho que só têm pontos positivos; não vejo em nenhum momento pontos negativos. Não me estressa, não me cria problemas essa questão dos meninos virem para cá, nem em termos de quantidade de acadêmicos que vem pra cá (P1).

A minha atuação como preceptor, em todos os anos que eu trabalhei, sempre me trouxe beneficios aqui para a minha prática. Não só para mim, mas com outros profissionais da equipe também, os agentes de saúde, a enfermeira, isso ajuda muito na melhoria de cada um como profissional, e também no próprio trabalho que você realiza (P2). 
A prática do trabalho interdisciplinar e interprofissional não foi observada nos estágios alvo desta investigação, conforme previsto nas DCNs (BRASIL, 2001), embora existam na literatura trabalhos que mostram o Pró e Pet-Saúde como Programas que promovem, além da integração ensino-serviço, a formação interprofissional e a aprendizagem em equipes interdisciplinares (BATISTA et al., GONÇALVES et al., 2015).

O trabalho interprofissional é a proposta para a formação de profissionais da área de saúde, traduzido em novos conhecimentos e posturas, substituindo o trabalho multiprofissional em que os profissionais de saúde atuam lado a lado, mas com baixa integração (CYRINO et al., 2014). A compartimentalização da prática é comum em equipes dos serviços de saúde, pois transpor a discussão da interdisciplinaridade para o campo das práticas é enfrentar o antagonismo entre o modelo da lógica profissional e o modelo de colaboração interprofissional (FONTANA, 2018).

A permanência dos estudantes no serviço deve produzir a reflexão sobre os cuidados e as práticas voltadas ao usuário. Trazer a atuação interprofissional como proposta educativa é necessário para melhorar o diálogo entre ensino-serviço, buscando a transformação da prática, levando a uma formação profissional em saúde que englobe o trabalho em equipe e o vínculo, estabelecendo estratégias eficazes de intervenção na produção de saúde, definidas a partir da demanda da população (ALBUQUERQUE et al., 2008).

Observou-se a utilização da abordagem de promoção de saúde com enfoque integral, segundo modelo de atenção apregoado pelo SUS na Política Nacional de Promoção à Saúde, com ruptura da formação prescritiva em odontologia para uma formação que permeia os princípios, os conceitos e a transversalidade da promoção da saúde (BRASIL, 2014). Ou seja, reduzir a vulnerabilidade à saúde, não se restringindo à área de formação de saúde bucal, mas, sim, aos vários determinantes sociais de saúde, contemplando alimentação saudável, prática de atividade física e estímulo à cultura de paz.

É válido dispor que pontos críticos ainda precisam ser superados e ilustrados pelos resquícios da formação biologicista/fragmentada. Esses profissionais raramente reproduzem no serviço a abordagem interdisciplinar, resultando na sobreposição das ações de cuidado, sendo necessário fortalecer e sensibilizar os espaços de ensino-aprendizagem no intuito de formar profissionais cada vez mais próximos das DCNs.

\section{CONCLUSÃO}

O estudo demonstrou o fortalecimento da atenção básica no exercício da prática profissional, proporcionado pela introdução das DCNs por meio do PPC do curso de odontologia e do PET-Saúde.

O planejamento compartilhado demonstrou a consolidação de um novo modo de pensar no processo formativo, considerando as demandas sociais como iniciativas para a aprendizagem e a produção da saúde. Reconhecer e destacar os preceptores como facilitadores do processo de ensino-aprendizagem é importante para a valorização e estímulo desses profissionais.

Em relação à interdisciplinaridade e ao trabalho interprofissional, estes ainda apresentam-se como dificuldades a serem superadas para os estágios e serviços de saúde. São barreiras que deverão ser transpostas por meio da educação permanente envolvendo as IES, com vistas a aperfeiçoar a formação dos egressos, dos discentes e dos preceptores, propondo transformações na prática do cuidado existente.

Os estágios do curso de odontologia apresentaram-se condizentes com as DCNs. A ampla participação desses atores confere características especiais no desenvolvimento dos estágios como modelos a serem seguidos, assim como na aplicação das políticas públicas no campo da educação e da formação em saúde.

Os estágios analisados representam uma possibilidade de aprendizagem, reflexão e compreensão do SUS, o que, sem dúvida, contribui com o conhecimento e vivências dos limites e desafios colocados para a formação acadêmica na área.

\section{REFERÊNCIAS}

ALBUQUERQUE, V. S.; GOMES, A. P.; REZENDE, E. C. H. A.; SAMPAIO, M. X.; DIAS, O. V.; LUGARINHO, R. M. A integração ensino-serviço no contexto dos processos de mudança na formação superior dos profissionais da saúde. Revista Brasileira de Educação Médica, Rio de Janeiro, v. 32, n. 3, p. 356-362, 2008.

ALMEIDA, L. P.; VON, G.; FERRAZ, C. A. Políticas de formação de recursos humanos em saúde e enfermagem. Revista Brasileira de Enfermagem, Brasília, v. 6, n. 1, p. 31-35, 2008. ANDRADE, S. R.; BOESHS, A. E.; BOESHS, C. G. E. Percepções de enfermeiros docentes e assistenciais sobre a parceria ensino-serviço em unidades básicas de saúde. Interface: Comunicação, Educação e Saúde, Botucatu, v. 19, n. 54, p. 537-547, 2015.

BARDIN, L. Análise de conteúdo. 6. ed. São Paulo: Edições 70, 2011. 279 p. 
BATISTA, S. H. S. S.; JANSEN, B.; ASSIS, E. Q.; SENNA, M. I. B.; CURY, G. C. Formação em saúde: reflexões a partir dos Programas Pró-Saúde e PET-Saúde. Interface: Comunicação, Saúde e Educação, Botucatu, 19(1s), p. 743-752, 2015.

BRASIL. Conselho Nacional de Educação. Câmara de Educação Superior. Parecer no 1.133 de 7 de outubro de 2001. Diretrizes Nacionais do Curso de Graduação em Odontologia. Brasília, DF: CNE, 2001.

BRASIL. Conselho Nacional de Saúde. Resolução no 466, de 12 de dezembro de 2012. Aprova as diretrizes e normas regulamentadoras de pesquisas envolvendo seres humanos. Brasília, DF: CNS, 2012.

BRASIL. Ministério da Saúde. Portaria interministerial no 1.802, de 26 de agosto de 2008. Institui o Programa de Educação pelo Trabalho para a Saúde - PET-saúde. Brasília, DF: MS, 2008.

BRASIL. Ministério da Saúde. Secretaria de Vigilância em Saúde. Secretaria de Atenção à Saúde. Política nacional de promoção da saúde. Brasília: MS, 2014. 60 p. (Série B. Textos Básicos de Saúde).

BRASIL. Ministério da Saúde. Portaria interministerial $n$ o 2.101, de 3 de novembro de 2005. Institui o Programa Nacional de Reorientação da Formação Profissional em Saúde - Pró-saúde -, para os cursos de Graduação em Medicina, Enfermagem e Odontologia. Brasília, DF: MS, 2005.

BRASIL. Edital no 14 de março de 2013. Seleção para o Programa de Educação pelo Trabalho para a Saúde (PET-Saúde), o PET-Saúde/Rede de atenção à saúde. Brasília, DF, 2013.

BREHMER, L. C. F.; RAMOS, F. R. S. O modelo de atenção à saúde na formação em enfermagem: experiências e percepções. Interface: Comunicação, Saúde e Educação, Botucatu, v. 20, n. 56, p. 135-145, 2016.

CYRINO, E. G.; FIGUEIREDO, A. M.; LOPES, C. V.; MONTEIRO, E. M. M.; FRONZA, F. L.; SANTOS, F. L.; RODRIGUES, I. S.; DISEGNA, J.; COSTA, J. F. L.; FREITAS, M. S. B.; DOMINGUES, S. M.; SANTOS, V. L.; RODRIGUES, V. E. R. Políticas públicas indutoras de mudanças nas graduações da saúde na perspectiva do fortalecimento do Sistema Único de Saúde do Brasil: os caminhos, a evolução e os desafios do Pet-Saúde. Ribeirão Preto: Funpec, 2014.

FERREIRA, M. L. S. M.; COTTA, R. M. M.; OLIVEIRA, M. S. Construção coletiva de experiências inovadoras no processo ensino-aprendizagem na formação de profissionais da saúde. Revista Brasileira de Educação Médica, Rio de Janeiro, v. 33, n. 2, p. 240-246, 2009.

FERREIRA, V. S. C.; ANDRADE, C. S.; FONTES, A. M. D. L.; ARAUJO, M. C. F.; ANJOS, S. D. S. Modos de cuidar e educar a partir do Programa de Educação pelo Trabalho para a Saúde. Interface: Comunicação, Saúde e Educação, Botucatu, v. 19, n. 1s, p. 857-868, 2015.

FONTANA, R. T. O processo de educação em saúde para além do hegemônico na prática docente. Revista Contexto e Educação, ljuí: Editora Unijuí, v. 33, n. 106, p. 84-98, 2018.
GONÇALVES, R. C. R.; GONÇALVES, L. G.; COVRE, L.; LAZARINI, W. S.; ARAUJO, D. M. Nós em rede: vivências da parceria ensino-serviço produzidas pelo Programa de Educação pelo Trabalho para a Saúde. Interface: Comunicação, Saúde e Educação, Botucatu, v. 19, n. 1s, 903-912, 2015.

LIMA, P. A. B.; ROZENDO, C. A. Desafios e possibilidades no exercício da preceptoria do Pró-PET-Saúde. Interface: Comunicação, Saúde e Educação, Botucatu, v. 19, n. 1s, p. 779791, 2015.

MINAYO, M. C. S. O desafio do conhecimento: pesquisa qualitativa em saúde. 14. ed. São Paulo: Hucitec, 2014.

MORAES, B. A.; COSTA, N. M. S. C. Compreendendo os currículos à luz dos norteadores da formação em saúde no Brasil. Revista da Escola de Enfermagem da USP (Online), v. 50, p. 9-16, 2016.

SILVA, M. A. M.; AMARAL, J. H. L.; SENNA, M. I. B.; FERREIRA, E. F. O Pró-Saúde e o incentivo à inclusão de espaços diferenciados de aprendizagem nos cursos de odontologia no Brasil. Interface: Comunicação, Saúde e Educação, Botucatu, v. 16, n. 42, p. 707-717, 2012.

TOASSI, R. F. C.; DAVOGLIO, R. S.; LEMOS, V. M. A. Integração ensino-serviço-comunidade: o estágio na atenção básica da Graduação em Odontologia. Educação em Revista, Belo Horizonte, v. 28, n. 4, p. 223-242, 2012.

UFG. Universidade Federal de Goiás. Faculdade de Odontologia. Guia do Estágio em Odontologia Coletiva II. Goiânia, GO: FO; UFG, 2015.

VASCONCELOS, A. C. F.; STEDEFELDT, E.; FRUTUOSO, M. F. $P$. An experience of teaching-service integration and change of professional practices: healthcare professionals speak out. Interface: Comunicação, Saúde, Educação, Botucatu, v. 20, n. 56, p.147-153, 2016. 